\title{
Metodologias ativas como práxis interdisciplinar na educação profissional e
}

\section{tecnológica}

\author{
Active methodologies as interdisciplinary praxis in vocational and technological education \\ Metodologías activas como praxis interdisciplinar en la educación profesional y tecnológica
}

Recebido: 08/11/2021 | Revisado: 23/11/2021 | Aceito: 08/12/2021 | Publicado: 17/12/2021

\author{
Marcos Sérgio Carvalho Rebouças \\ ORCID: https://orcid.org/0000-0002-6120-8361 \\ Instituto Federal do Rio Grande do Norte, Brasil \\ E-mail: marcossergio10@hotmail.com \\ Diogo Pereira Bezerra \\ ORCID: https://orcid.org/0000-0002-0159-4117 \\ Instituto Federal do Rio Grande do Norte, Brasil \\ E-mail: diogo.bezerra@ifrn.edu.br
}

\begin{abstract}
Resumo
O presente estudo respalda-se na luta pela superação dos conhecimentos fragmentados e propõe refletir na necessidade de metodologias que instigue os discentes a interagir de maneira eficaz no mundo em que vivem perante a construção de saberes integrado às mais diversas práticas sociais. Ele tem por principal objetivo produzir subsídios teórico-metodológicos, por meio de uma oficina, com vistas à potencialização de práticas interdisciplinares, construídas a partir das metodologias ativas, que proporcione a inter-relação entre disciplinas propedêuticas e técnicas no contexto da Educação Profissional e Tecnológica. A pesquisa pautou-se numa abordagem qualitativa sob uma perspectiva de Pesquisa-ação e desenvolveu-se com base na pedagogia histórico-crítica. Os dados e informações foram coletados e gerados através de Escala Likert, apanhado bibliográfico, roda de conversa e questionário. Na oportunidade aplicou-se uma oficina intitulada "Consciência Ecológica" utilizando-se de Metodologias Ativas. A proposta foi trabalhada junto aos discentes do ensino médio integrado em Agroecologia e Meio ambiente e se mostrou uma possibilidade de estratégia viável na luta pela formação de sujeitos emancipados que enxergam na oportunidade do saber-fazer interdisciplinar, possibilidades de aprendizagens significativas, alinhadas às complexidades do mundo contemporâneo.
\end{abstract}

Palavras-chave: Interdisciplinaridade; Educação profissional e tecnológica; Metodologias ativas; Ensino.

\begin{abstract}
This study is based on the struggle to overcome fragmented knowledge and proposes to reflect on the need for methodologies that encourage students to interact effectively in the world in which they live in view of the construction of knowledge integrated to the most diverse social practices. Its main objective is to produce theoreticalmethodological subsidies, through a workshop, with a view to enhancing interdisciplinary practices, built from active methodologies, which provide the interrelationship between introductory and technical disciplines in the context of Professional and Technological Education. The research was based on a qualitative approach from an Action Research perspective and was developed based on the historical-critical pedagogy. Data and information were collected and generated through a Likert scale, bibliographic collection, conversation wheel and questionnaire. On that occasion, a workshop entitled "Ecological Awareness" was applied using Active Methodologies. The proposal was worked on with EMI students in Agroecology and Environment and proved to be a possibility of a viable strategy in the struggle for the formation of emancipated subjects who see in the opportunity of interdisciplinary know-how, possibilities for significant learning, in line with complexities of the contemporary world.
\end{abstract}

Keywords: Interdisciplinarity; Professional and technological education; Active methodologies; Teaching.

\section{Resumen}

El presente estudio se sustenta en la lucha por la superación de saberes fragmentados y propuestas para reflexionar sobre la necesidad de metodologías que estimulen a los estudiantes a interactuar de manera efectiva en el mundo en el que viven en vista de la construcción del conocimiento integrado con las más diversas prácticas sociales. Su principal objetivo es producir subsidios teórico-metodológicos, a través de un taller, con miras a potenciar prácticas interdisciplinarias, construidas a partir de metodologías activas, que brinden una interrelación entre disciplinas introductorias y técnicas en el contexto de la Educación Profesional y Tecnológica. La investigación se basó en un enfoque cualitativo bajo una perspectiva de Investigación Acción y se desarrolló con base en la pedagogía históricocrítica. Los datos y la información fueron recolectados y generados a través de una escala Likert, colección bibliográfica, rueda de conversación y cuestionario. En esa ocasión, se aplicó un taller titulado "Conciencia 
Ecológica" utilizando Metodologías Activas. La propuesta se trabajó con estudiantes de bachillerato integrados en Agroecología y Medio Ambiente y se muestra como una posibilidad de una estrategia viable en la lucha por la formación de sujetos emancipados que ven en la oportunidad de un saber hacer interdisciplinario, posibilidades de aprendizaje, alineadas. con las complejidades del mundo contemporáneo.

Palabras clave: Interdisciplinariedad; Educación profesional y tecnológica; Metodologías activas; Enseñanza.

\section{Introdução}

As rápidas e cada vez mais drásticas transformações sociais, econômicas, tecnológicas e culturais que se dão no seio da sociedade afetam diretamente as instituições de ensino e estas para continuarem cumprindo funções precisam repensar o seu agir pedagógico. Nesse contexto, um dos grandes desafios que a escola do século XXI enfrenta como afirma Bianconcini de Almeida (2008) é fazer com que os estudantes permaneçam usufruindo do ensino para que aprendam e se desenvolvam a fim de inserir-se nessa nova sociedade. A partir deste cenário, temas como Interdisciplinaridade e Metodologias Ativas deve ser alvo de atenção especial no contexto da Educação Profissional e Tecnológica (EPT) ao ofertar cursos que visam qualificar os sujeitos para o mundo do trabalho através de uma formação omnilateral e politécnica, termos estes de origem marxista, que têm por pressuposto, de acordo com Saviani (2003), o trabalho como princípio educativo, abordagem essencial na formação integral dos homens.

Sob essa nova organização e volátil organização da sociedade e necessidade de adaptação dos sistemas de ensino, procedimentos metodológicos que apelem ao diálogo entre as áreas do conhecimento e favorecem o acesso a maneiras diferenciadas de construção de saberes constituem alternativas ao modelo tradicional (Rebouças, 2021). Essas são situações que imergem o sujeito da aprendizagem com questões cotidianas, contemplando, inclusive, aspectos do modelo de ensino sugerido e praticado por Freire (1996). Junto a essas opções estão as Metodologias Ativas, capaz de auxiliar os discentes a desenvolver sua autonomia na resolução de problemas, proatividade e criticidade nas tomadas de decisões (dos Santos et al., 2021).

Destarte, nesta pesquisa buscou-se produzir subsídios teórico-metodológicos, por meio de uma oficina, aplicada junto aos discentes do Instituto Federal de Educação, Ciência e Tecnologia do Rio Grande do Norte, Campus Ipanguaçu, para a potencialização de práticas interdisciplinares na Educação Profissional e Tecnológica (EPT) a partir das metodologias ativas. Esta pesquisa também permitiu repensar estratégias pedagógicas que valorizasse o trabalho, entendido aqui como um princípio educativo, a exemplo do que defende o IFRN em seu Projeto Político Pedagógico - PPP, corroborando para promover uma educação crítica que auxilie os estudantes em sua formação cidadã.

\section{Metodologia}

A pesquisa realizada classifica-se como qualitativa, visto que "leva em conta a junção entre o sujeito e o objeto e busca fazer uma exposição e elucidação dos significados que as pessoas atribuem a determinados eventos” (Ludwig, 2014, p. 8). Essa investigação ao tratar dos objetivos se caracterizou como pesquisa explicativa, a qual identificou os fatores que contribuem para a ocorrência fenômenos (os estudados). Quanto aos procedimentos técnicos, o estudo é tipificado como uma pesquisa-ação cujo foco centra-se na resolução de problemas, tomada de consciência ou produção de conhecimento (Thiollent, 2011). O processo de utilização da Pesquisa-ação foi dividido em quatro fases a saber: fase exploratória, fase principal, fase de ação e fase de avaliação (Thiollent, 2011).

A pesquisa foi aplicada com um grupo focal de 09 alunos do Ensino Médio Integral em Agroecologia e em Meio Ambiente. Participaram de uma oficina virtual intitulada "Consciência ecológica" e que abordou em cada um dos seus quatro módulos temas pertinentes ao momento em que vive o Brasil e o mundo, a saber foi discutido o uso dos agrotóxicos, a importância da água e a necessidade do uso racional dos recursos institucionais. Todas os temas geradores foram discutidos à 
luz de Metodologias Ativas (sala de aula invertida, gamificação e aprendizagem baseada em problemas, respectivamente) e ministrados através da modalidade Ensino Remoto Emergencial em virtude da pandemia da Covid-19 (Magalhães et al., 2020). A oficina durou 28 dias e teve 4 encontros síncronos, essenciais para o acompanhamento, discussão e controle.

A priori, já no início da oficina, aplicou-se uma Escala Likert contendo 9 proposições e visando a coleta de dados que pudessem verificar o nível de integração entre as disciplinas propedêuticas e de áreas técnicas no contexto do Instituto Federal de Educação, Ciência e tecnologia do Rio Grande do Norte - IFRN Campus Ipanguaçu. As proposições variaram desde a ministração de aulas de campo até atividades realizadas concomitantemente por mais de um professor, atuantes em diferentes áreas. O resultado de aplicação da escala ratificou uma expectativa já criada que aponta para a ausência de práticas interdisciplinares continuas que façam uso de metodologias ativas e corrobore para com uma formação ampla e emancipatória.

$\mathrm{Na}$ etapa final, de tratamento dos resultados, inferência e interpretação, fez-se uma análise, a mais profunda possível, das categorias com base no referencial teórico da pesquisa, predominantemente fundamentados nos autores citados, e considerando todas as interações, eventos e percepções possíveis durante a oficina. Toda a categorização, da fase inicial à final, seguiu critérios de filtragem, aglutinação e evolução. As categorias finais, construídas com o auxílio do software MAXQDA Analytics Pro 2020, programa acadêmico utilizado em pesquisas qualitativas, permiti-nos ter uma visão de todo o processo, até a percepção dos resultados, de modo prático, organizado e representativo.

\section{Resultados e Discussão}

Os dados obtidos através do questionário diagnóstico e tratados pela escala Likert, aponta para a urgente necessidade de subsídios que auxiliem os docentes em sua atividade quando o que está em jogo é a busca da integração do ensino regular com a educação profissional e tecnológica. As respostas deixam claro que a carência de práticas que contrapõe ao modelo de educação fragmentária e evidencia a importância de uma formação integral dos indivíduos visto essa ser uma das maiores buscas da formação marxiana. Sabendo-se disso e já partindo para a análise categorial faz-se necessário ressaltar que nesta pesquisa por questão de ética os participantes são identificados da seguinte forma: P1, participante 1; P2, participante 2 e assim, sucessivamente.

Feito a verificação inicial e constatado o que está patente nas principais bibliografias sobre as dificuldades de inovações metodológicas e práticas integradoras, inicia-se analises e inferências com base em Bardin (2011). Constrói-se as categorias, refinadas e aglutinadoras, predominantemente oriunda das percepções e falas extraídas durante as rodas de conversas que aconteceram em caráter avaliativo durante os módulos da oficina. Assim, ciente da trivialidade quanto aplicação das etapas de uma análise de conteúdo, parte-se diretamente para os discursões das categorias finais chamadas, em nosso texto, apenas de categorias.

Na primeira categoria, intitulada "Educação Emancipatória e os sujeitos", ao abordar os três temas geradores da oficina e discutindo-os sob as mais diversas perspectivas, umas das preocupações foi justamente o preenchimento de requisitos que tornassem a prática libertadora, emancipatória e enviesada para uma experiência integrada. Daí buscou-se trabalhar sob o enfoque de uma formação crítica por ser esta encarada como um modelo em que todos os atores do processo educacional, formais ou informais, primam pelo despertar de uma visão reflexiva e transformadora nos educandos.

Marx entende o movimento histórico da humanidade como uma relação do homem com o meio e dos homens entre si. O pensador concebe a educação como uma ferramenta importante no combate à alienação ao acreditar que dela surgem novos sujeitos, capazes de tomar decisões e intervir na sociedade, de forma contra hegemônica, quando influenciados por um modelo que propicie a efervescência do pensamento crítico e não apenas forme homens para atender os interesses do mercado como faz a ordem capitalista. Ao tratar desse modelo de educação Almeida (2010) afirma que 
O sujeito histórico é permeado pela educação. O educar é o meio pelo qual o homem se constrói historicamente. No entanto, no interior da ordem capitalista, educadores e alunos são considerados em termos daquilo que podem produzir; as produções são consideradas como valiosas, como as notas, os exames, as qualificações. Os educadores acabam sendo considerados como meros trabalhadores e mercadorias em produção (Almeida, 2010, p.255).

Diante disso, na tentativa de minimizar o modus operandi da lógica burguesa quanto ao educar e acreditando que a educação dialética pode se configurar o caminho para a superação da estrutura imposta que visa preparar os sujeitos exclusivamente para fins econômicos e de adestramento, estruturou-se a oficina de modo a possibilitar as mais profundas reflexões. Isso pôde ser comprovado durante os debates e as rodas de conversas ao tratar de assuntos voltados às causas ambientais em que os próprios participantes conseguiram perceber vinculações entre práticas sociais e o mundo que o cerca.

Percebe-se aí, durante as conversas, o início formativo de uma consciência emancipada e que consegue compreender de modo significativo a relação dos conteúdos e saberes com os movimentos dos sujeitos. Isso reflete pensamentos de Paulo Freire, ao defender que o diálogo é a essência da educação como prática emancipatória, portanto um mecanismo de liberdade que aproxima e humaniza o homem. Concordando com tal pensamento, a interlocução foi elevada a uma das principais marcas dos encontros síncronos durante a oficina, das interações via Google Sala de Aula e das mensagens de WhatsApp.

Perante as rodas de conversas houve intenso diálogo e esse interacionismo, característico de uma pedagogia Históricocrítica, que lida com a prática social, intenciona articulações e mobilizações de saberes amparados por diferentes posições do sujeito. Isso, por sua a vez, contribui com o rompimento da concepção disciplinar tradicional e fortalece aprendizagens interdisciplinares suscitadas na realidade concreta do ambiente em que vivem os discentes. Logo, a comunicação entre eles e a relação que se dá entre professor (pesquisador) e aprendente (participante) favorece, segundo Freire (1987), o processo de ensino e aprendizagem. É nessa prática que ambos desenvolvem uma relação horizontal de respeito e afetividade. Isso torna o diálogo componente relevante para uma aprendizagem significativa e potencializadora das reflexões entre os sujeitos.

Portanto, a oficina conseguiu mostrar uma estratégia que além de melhorar a competência comunicacional e despertar, nos envolvidos, consciência crítica, traz a esperança, sentimento que para Freire (1996) deve ser vista como uma necessidade ontológica e virtude imprescindível na educação. Isso é muito salutar visto que a EPT requer uma aprendizagem contextualizada, significativa, mediada pelas tecnologias de informações e comunicação (TDIC's), voltada às habilidades de resolver problemas e ao uso da inteligência de modo efetivo na complexidade do ambiente laboral e do meio social. Para isso convém defender que o uso das metodologias ativas quando pensada sob as bases do materialismo dialético dispõe de grande capacidade disruptiva entre a pedagogia tradicional acrítica e as tendências inovadoras enviesadas por uma corrente marxiana.

A segunda categoria, intitulada "Interdisciplinaridade e os desafios da EPT", foi extraída a partir de diálogos que considerou a forte inter-relação entre diferentes disciplinas construindo assim um discurso interdisciplinar e que se configurou objeto de admiração e interesse por parte da turma. Todas as falas e transcrições resultantes das conversas agruparam-se em torno da categoria "Inter-relação e diálogos entre as disciplinas propedêuticas e técnicas", cuja efetivação aponta possibilidades para a EPT. Do mesmo modo, tem-se que a contextualização, conceito importante e bastante utilizado na oficina que ao vincular aprendizagens à sua origem e aplicação, constitui estratégia eficaz para uma abordagem significativa. Esses conceitos juntam em torno de si a aplicação dos saberes à realidade concreta.

Desse modo, com o intuito de alcançar os principais objetivos dessa pesquisa, a aplicação do produto educacional focou na interdisciplinaridade que é um dos grandes desafios da EPT e que na concepção de Fazenda (2008) representa uma estratégia crítica da forma de educar e de construir saberes. As variedades de materiais escolhidas sob as mais diversas áreas e as pesquisas cujas orientações foram repassadas aos participantes primaram pelo diálogo entres as disciplinas. A intenção sempre foi mostrar que os conhecimentos quando acessados diante da realidade se entrelaçam e conversam de forma que os limites entre eles são por vezes linhas tênues, difíceis de encontrar, pois esse tipo de abordagem prioriza situações e não 
disciplinas isoladas. Nesta concepção, tem-se que o envolvimento com meio e a remoção da ruptura didática do saber-fazer ou da teoria-prática devem ser superadas.

No projeto interdisciplinar não se ensina, nem se aprende: vive-se, exerce-se. A responsabilidade individual é a marca do projeto interdisciplinar, mas essa responsabilidade está imbuída do envolvimento - envolvimento este que diz respeito ao projeto em si, às pessoas, e às instituições a ele pertencentes (Fazenda, 2008, p, 17).

Considerando o exposto e com o objetivo de fomentar o diálogo entre as disciplinas propedêuticas e de base técnicas, os participantes foram orientados a refletirem sobre a inserção dos temas na realidade concreta e incentivados a perscrutar as relações entre os módulos que constam nos cursos técnicos em que estão matriculados. Essa estratégia foi bastante eficaz visto os interessantes debates que ocorreram durante a oficina. Neste sentido, a promoção dessa inter-relação entre áreas do conhecimento e cotidiano pode influenciar na percepção dos educandos quanto à importância de cada módulo em seu processo de formação. O foco da categoria "Interdisciplinaridade e desafios da EPT" gira em torno da importância de uma mudança drástica na prática pedagógica que converge no ponto de integração entre os diferentes saberes. Já na primeira roda de conversa percebeu-se nos participantes o que Fazenda (2008, p. 17) define como "[...] atitude de ousadia e busca frente ao conhecimento", mostrando assim as contribuições das metodologias ativas no desenvolvimento da interdisciplinaridade.

$\mathrm{Na}$ segunda roda de conversa, quando solicitado aos participantes para refletir sobre quais disciplinas estavam sendo envolvidas (dialogando entre si) no tema "uso da água", por exemplo, conforme estava sendo debatido, a aprendente P3 destacou que: "[...] as questões do joguinho envolveram várias matérias para ensinar o mesmo assunto. Podemos estudar sobre a água em biologia, química, geografia, ecologia, história, irrigação e outras” e essa percepção por parte dos educandos foi resultante da construção de uma consciência pautada na realidade concreta cujo descobrimento não pode ser concebido na singularidade dos saberes. Isso tem respaldo em Fazenda (2001) quando afirma que essa consciência da interdisciplinaridade favorece a integração curricular. Ainda, segundo a autora, tal entendimento por parte da instituição e docentes, tem a capacidade de estimulá-los na reorganização das áreas do conhecimento, na organização do currículo e na busca por metodologias inovadoras.

Nesse sentido, ainda corroborando com P3, o participante P6, ao relatar sua experiência na oficina, afirma: “[...] vi que as disciplinas têm tudo a ver uma com as outras quando precisamos resolver problemas da vida real". Esse entendimento por parte dos discentes configura-se um caminho interessante na construção de uma visão cada vez mais longe do saber fragmentado. Pois, "o modo de pensar fragmentário, linear, produz conhecimentos que, transformados em ação, trazem inúmeros problemas concretos ao conjunto da humanidade" (Frigotto, 1995, p. 49). E isso é fato em virtude de a produção do conhecimento não ser desvinculado dos conflitos que se estabelecem na sociedade, como a divisão do trabalho, por exemplo, que coopera com a alienação e exclusão dos homens. Logo, enxerga-se na interdisciplinaridade uma possibilidade de passagem dessa especialização do saber para uma concepção unitária vinculada à vida e, portanto, às relações sociais.

Esse sentimento de utilidade e o entendimento de que o mundo é interdisciplinar chama a responsabilidade das instituições de ensino para a inovação, e participação, com uma visão holística e não especializada, que as torne espaço de reflexão, de compartilhamento e de aprendizagens significativas. Das discussões prevalecentes nesta categoria final pode-se deduzir que a oficina, na ânsia de apontar um caminho a ser utilizado pelos docentes da EPT, ao fazer uso das metodologias ativas e despertar os participantes para a importância da transversalidade entre os saberes, pode favorecer a construção de uma visão integrada da realidade. Isso constitui uma das principais buscas da educação que tem o trabalho (saber-fazer) como princípio educativo. Antes de finalizar a discussão é importante frisar que se sabe do grande desafio teórico, epistemológico e metodológicos que é o fomento das inter-relações entre as disciplinas e para isso as metodologias ativas organizadas para esse fim conseguiram fazer com que cada disciplina respeitasse o limite da outra e ainda dialogassem rumo à construção de um 
saber cuja essência ampara-se nas bases conceituais da EPT (Souza \& Moraes, 2020).

Sobre terceira e última a categoria "Metodologias Ativas para um novo tempo" é bastante pertinente refletir sobre as tecnologias e os novos desafios da educação que resume a necessidade da inserção cada vez mais efetiva das tecnologias digitais disponíveis no ambiente educacional a fim de atender às novas exigências de um mundo dependente de rapidez, economia de recursos e que oportunize aos nativos digitais vivenciarem situações envolventes às quais já estão acostumados. Sinteticamente, ela parte da ideia de que na vida todos tem a missão de resolver problemas e para que isso ocorra vários saberes precisam ser mobilizados. Entre as metodologias ativas utilizadas na oficina, tem-se a sala de aula invertida, modelo otimizador do processo de ensino e aprendizagem que moderniza a construção do conhecimento e requer a autonomia por parte do discente; A gamificação, que fortalece a importância do lúdico na aprendizagem e tratou de atrelar divertimento à aprendizagem significativa que, conforme já descrito, proporciona aos jovens uma situação confortável diante dos objetos de estudo; e, por fim, tem-se a Aprendizagem Baseada em Problemas e a capacidade que essa metodologia dispõe à instauração de uma formação integral.

Essas metodologias ativas, que de acordo com Moran (2018, p. 4), "num mundo conectado e digital, expressam-se por meio de modelos de ensino híbridos, com muitas possíveis combinações e [...] traz contribuições importantes para o desenho de soluções atuais para os aprendizes de hoje", se colocaram como base de todos os encontros e, instituídas através de tecnologias permitiram alinhar os discentes ao seu contexto social mediado pela digitalização. Frisa-se que nos encontros, os aprendentes puderam explorar um espaço democrático, construído para as trocas, permeado por um clima bastante amistoso e que considerou os saberes ancoras e o cotidiano de cada participante. Pois, mais do que nunca, torna-se preciso apropriar-se de uma educação problematizadora, vinculada a realidade, visto que, numa perspectiva de libertação, a vivência dos estudantes passa a ser a fonte primária na elaboração do currículo (Freire, 1987). Nessa pesquisa, essas metodologias foram usadas para potencializar a interdisciplinaridade. Diante dos fatos, viu-se os objetivos de a oficina ser atingidos, promovendo a interdisciplinaridade e sinalizando que inovação com planejamento se faz urgente e necessário nas instituições de ensino, principalmente nas que ofertam a EPT.

Durante as interações entre os participantes e o pesquisador, perante a proposta interdisciplinar, buscou-se utilizar de uma didática que proporcionasse uma forte aproximação e os possibilitasse refletir, modificar e quando necessário construir novas interpretações acerca dos temas apresentados, pois o discente nesta pesquisa sempre foi tratado como o agente ativo da aprendizagem.

Com base no detalhamento categorial infere-se que práticas interdisciplinares apoiadas por tecnologias e metodologias que situe o aprendente no centro do processo ainda não se faz presente com a frequência desejada na instituição em que eles estão matriculados e o modo de conduzir o ensino e aprendizagem na oficina gerou admiração. Salienta-se que existem muitos entraves para que mudanças aconteçam na educação que estão para além das capacidades dos docentes ou mesmo institucionais. Para Machado (2000), por exemplo, o fato de os currículos seguirem rígida linearidade é um fator que dificulta o trabalho interdisciplinar. A cultura, fatores econômicos, políticos e sociais também contribuem para com a lentidão no usufruto das tecnologias digitais no ensino. Daí a ousadia dessa pesquisa e do consequente produto educacional em propor o uso das metodologias ativas sob uma práxis instigadora do diálogo entre as disciplinas.

De fato, Bergmann e Sams (2016) defendem que neste tipo de metodologia os encontros síncronos entre o educador e os educandos são dedicados a ação de criar, avaliar e consolidar habilidades superiores de pensamento dentro da temática estudada. Assim, deixa-se que atividades básicas como pesquisar conceitos, por exemplo, sejam realizadas autonomamente, sob a responsabilidade dos aprendentes. Frisa-se que durante a oficina virtual, os participantes foram orientados a acessar vídeos, textos e outras fontes de informações, além de realizar pesquisas orientadas, antes dos encontros realizados via Google Meet. Durante a oficina constatou-se que, principalmente na EPT, usar a Gamificação para no processo de ensino e 
aprendizagem é algo muito proveitoso.

Durante a prática, a vinculação dos temas e abordagens com situações reais foram decisivas para o bom engajamento de todos, fazendo valer o que o professor Demerval Saviani defende na pedagogia histórico-crítica ao considerar que uma das funções da escola é possibilitar o acesso aos conhecimentos relevantes, previamente produzidos e sistematizados. Vale considerar que na EPT, práticas inovadoras devem ser cada vez mais utilizadas e estimuladas para que o discente deixe de ser apenas um agente passivo em espaço de ensino e desperte o interesse e a curiosidade em solucionar possíveis problemas que surgirão nas diversas práticas sociais, incluindo o mundo do trabalho. Em tudo isso, as metodologias e estratégias utilizadas na oficina se mostraram necessárias e pertinentes.

\section{Conclusão}

Conclui-se que na tentativa de superação do saber fragmentado e descolado das práticas sociais, o uso das metodologias ativas permeadas pela interdisciplinaridade se mostrou instigante, problematizador, reflexivo, crítico e utilizável na ampla formação de sujeitos, capazes de tomar decisões sobre o mundo do trabalho e a complexidade da vida social. A avaliação da prática em formato de oficina, apropriada nesta pesquisa, se deu através de rodas de conversas, análise dos diálogos e questionários. Estes apontaram resultados positivos e reforçaram o grau de abertura e consciência dos discentes quanto à necessidade de inovações no ambiente de aula. Houve consenso entre o público-alvo sobre a importância do saber interdisciplinar e das de metodologias ativas frente o desafio de ensinar e aprender com os nativos digitais, curiosos, rodeados por informações e adaptados à volatilidade, comum à sociedade contemporânea.

Entre os principais desafios em aplicar a oficina virtualmente, esteve o fato de nem todos terem acesso à tecnologias minimamente necessárias a um melhor aproveitamento e, devido isso, citarem algumas dificuldades, ainda que estas não foram suficientes para inviabilizar a participação e construção de saberes. Quanto às questões metodológicas, a priori, observou-se como entraves o engessamento cultural promovedor do receio pelo novo, as costumeiras burocracias curriculares, as rotinas organizacionais e a insuficiência do tempo estabelecido para algumas atividades em virtude do paralelismo entre eventos da oficina e aulas do ensino formal. Todavia, tais situações podem ser modificadas gradativamente através de diálogos profícuos e orientações, a exemplo do que aconteceu durante a aplicação do produto.

Portanto, buscou-se nesta pesquisa, como sugere o título, refletir sobre o aprendente ser o centro da aprendizagem a partir de uma práxis interdisciplinar. Pois, bem mais do que adotar estratégias de ensino que simplesmente facilite o trabalho docente, entende-se é urgente e necessário refletir sobre os processos que atendam ao que é preconizado pela EPT, como por exemplo, a superação de um modelo fragmentado e descolado da realidade concreta. Convém salientar que a simples adoção de metodologias sem o devido planejamento e amparo nas bases conceituais transformadoras não contribui para a construção do sujeito emancipado que enxerga na oportunidade do saber-fazer interdisciplinar, possibilidades de aprendizagens significativas, alinhadas às complexidades do mundo contemporâneo. Mas que isso é preciso ousadia, ação e proatividade frente os carecimentos, muitas vezes negligenciados, por aqueles que estão imersos no ambiente em que a educação deve ser sempre transformadora.

\section{Referências}

Almeida, M. E. B. (2008). Tecnologias na Educação: Dos caminhos trilhados aos atuais desafios. BOLEMA: Boletim de Educação Matemática, 21(29), 99129. https://www.periodicos.rc.biblioteca.unesp.br/index.php/bolema/article/view/1723

Almeida, N. R. D. (2010). Educação para além da formação do trabalhador alienado. Educar em Revista, (spe2), 251-258. https://doi.org/10.1590/s010440602010000500015

Bardin, L. (2011). Análise de conteúdo. Almedina. 
Research, Society and Development, v. 10, n. 16, e500101622962, 2021

(CC BY 4.0) | ISSN 2525-3409 | DOI: http://dx.doi.org/10.33448/rsd-v10i16.22962

Bergmann, J., \& Sams, A. (2016). Sala de aula invertida: Uma metodologia ativa de aprendizagem. LTC.

Descartes, R. (1978). Discurso sobre o método. Hemus.

Fazenda, I. C. A. (2008). Interdisciplinaridade-transdisciplinaridade: visões culturais e epistemológicas. In: Fazenda, I. C. A. (Org.). O que é interdisciplinaridade? Ed. Cortez. p. 17-28

Fazenda, I., \& Arantes, C. (1999) Interdisciplinaridade: um projeto em parceria. Edições Loyola.

Freire, P. (1977). Extensão ou comunicação? Paz e Terra.

Freire, P. (1987). Pedagogia do oprimido. Paz e Terra.

Freire, P. (1996). Pedagogia da autonomia: saberes necessários à prática educativa. (21a.ed.), Paz e Terra.

Frigotto, G., Ciavatta, M., \& Ramos, M. (2005). A gênese do Decreto $n^{o}$ 5.154/2004: um debate no contexto controverso da democracia restrita. In: Frigotto, G., M. Ciavatta, \& M. Ramos (Orgs.), Ensino médio integrado: concepção e contradições (pp. 21-56). Cortez.

Gerhard, A. C., \& Rocha, J. F. B. (2012). A fragmentação dos saberes na Educação Científica Escolar na percepção de professores de uma escola de Ensino Médio. Investigações em Ensino de Ciências, 17(1), 125-145.

Glasser, W. (2001). Teoria da Escolha: uma nova psicologia de liberdade pessoal. Mercuryo.

Japiassu, H. (1976). Interdisciplinaridade e patologia do saber. Imago.

Ludwing, A. C. W. (2014). Métodos de pesquisa em educação. Revista Temas em Educação, 23(2), 204-233. https://periodicos.ufpb.br/index.php/rteo/article/view/18881/12572

Machado, N. J. (2000). Educação: projetos e valores. 3. ed. Escrituras (Ensaios Transversais).

Magalhães, J. H. S., Lima, C. B. P., de Souza, S. F., da Silva, S. A., \& de Aquino, F. J. A. (2020). Politecnia, cibercultura e ensino remoto emergencial: um estudo das práticas adotadas no Programa de Pós-Graduação em Educação Profissional e Tecnológica (PROFEPT). Research, Society and Development, 9(11), e089119427-e089119427.

Moran, J. (2015). Educação Híbrida: um conceito-chave para a educação, hoje. In: Bacich, L.; Neto, A. T.; Trevisani, F. M. (Orgs.). Ensino híbrido: personalização e tecnologia na educação. Penso.

Morin, E. (2000). A cabeça bem-feita: repensar a reforma; reformar o pensamento. Bertrand Brasil.

Piaget, J. (1973). Para onde vai a educação? Livraria José Olympo Editora/Unesco.

Rebouças, M. S. C. (2021). Metodologias Ativas sob uma práxis interdisciplinar na Educação Profissional e tecnológica. Dissertação (Mestrado em Educação Profissional e Tecnológica). Instituto Federal de Educação, Ciências e Tecnologia do Rio Grande do Norte - IFRN.

Santos, N. T., Santos Júnior, I. M., \& Pereira, G. A. F. (2021). Metodologias ativas na educação profissional e tecnológica: breve teorização. Research, Society and Development, 10(10), e354101018880-e354101018880.

Souza, J. J., \& Moraes, E. C. (2020). Educação profissional e tecnológica: percurso histórico e desafios na formação docente. Research, Society and Development, 9(12), e29491211069-e29491211069.

Thiollent, M. (2011). Metodologia da pesquisa-ação. (18a ed.), Cortez.

Zichermann, G., \& Cunningham, C. (2011). Gamification by Design: Implementing Game Mechanics in Web and Mobile Apps. Sebastopol, CA:O'Reilly Media, Inc. 